\title{
Gilles Philippe, Sujet, verbe, complément. Le moment grammatical de la littérature française (1890-1940)
}

\section{Paola Paissa}

\section{(2) OpenEdition}

1 Journals

\section{Édition électronique}

URL : https://journals.openedition.org/studifrancesi/41407

DOI : 10.4000/studifrancesi.41407

ISSN : 2421-5856

Éditeur

Rosenberg \& Sellier

\section{Édition imprimée}

Date de publication : 1 juillet 2004

Pagination : 236-237

ISSN : 0039-2944

\section{Référence électronique}

Paola Paissa, «Gilles Philippe, Sujet, verbe, complément. Le moment grammatical de la littérature française (1890-1940) », Studi Francesi [En ligne], 142 (XLVIII | I) | 2004, mis en ligne le 30 novembre 2015, consulté le 09 septembre 2021. URL : http://journals.openedition.org/studifrancesi/41407 DOI : https://doi.org/10.4000/studifrancesi.41407

Ce document a été généré automatiquement le 9 septembre 2021.

\section{(c) $(1) \odot$}

Studi Francesi è distribuita con Licenza Creative Commons Attribuzione - Non commerciale - Non opere derivate 4.0 Internazionale. 


\title{
Gilles Philippe, Sujet, verbe, complément. Le moment grammatical de la littérature française (1890-1940)
}

\author{
Paola Paissa
}

\section{RÉFÉRENCE}

GILLES PHILIPPE, Sujet, verbe, complément. Le moment grammatical de la littérature française (1890-1940), Paris, Gallimard, 2002.

1 C'est au tournant du XIX ${ }^{e}$ siècle et pendant la première moitié du $\mathrm{XX}^{\mathrm{e}}$, que se situe ce que G. Philippe désigne du nom de «moment grammatical» de la littérature française. A partir des premières réactions contre l'écriture réaliste et impressionniste (notamment la préface de Pierre et Jean, écrite par Maupassant en 1888), un important débat se développe en France qui ébranle l'épistémè littéraire traditionnelle et la remplace par une nouvelle doxa fondée sur une conception embryonnaire de ce que nous appellerions aujourd'hui la littérarité. Le questionnement qui engage pendant un demi-siècle littérateurs, critiques, linguistes, historiens, touche en fait au cœur de la définition de la littérature elle-même, puisqu'il porte sur la fonction de la grammaire dans l'analyse critique des textes littéraires, sur la légitimité des exemples d'auteur dans les grammaires, sur le rapport langue littéraire/langue commune et finalement sur les notions capitales de norme et de style.

Le processus de «grammaticalisation» du discours littéraire, très évident déjà dans les commentaires sur la prose impressionniste (chap.I) s'affirme nettement au cours de la «querelle sur le style de Flaubert» (1919-1920, chap.II). Les déviances de l'écriture artiste et les «fautes» de Flaubert laissent entrevoir que le discours littéraire est davantage affaire de grammaire et de syntaxe que de lexique et de rhétorique. Suivant G.Philippe, ce serait tout particulièrement la finesse critique de Proust qui, dans la controverse qui l'oppose à Thibaudet, aurait montré à quel point la nouvelle «vision» 
flaubertienne - la vision de l'intérieur - est avant tout redevable de l'inventivité grammaticale de l'auteur de Madame Bovary.

3 En ce sens le débat sur le style indirect libre (chap.III) en tant qu'effet littéraire ou fait grammatical apparait comme un prolongement de la querelle sur le style de Flaubert. Le débat, qui oppose les critiques français et allemands, se concentre sur l'imparfait littéraire et inaugure la réflexion sur le statut de la langue littéraire (discours particulier vs discours imposant une réception particulière). Une place capitale dans cette querelle est occupée par la vue innovante de C. Bally, qui anticipe les intuitions barthésiennes en reconnaissant au style indirect libre la fonction d'un marqueur de littérarité.

Un chapitre important (chap.IV) est consacré à la description de l'attitude des grammairiens face à la littérature: à la conception de la littérature comme «laboratoire» du génie grammatical (Brunot, La pensée et la langue, 1922), fait suite l'indifférence de Damourette et Pichon (Des mots à la pensée, 1927), qui n'utilisent la littérature que comme un gigantesque réservoir d'exemples. L'exclusion de la littérature du domaine d'investigation de la grammaire est fortement soutenue par Bally, pour qui la langue littéraire n'est qu'une variante déformée de la langue écrite standard (p.100), s'opposant à bien des égards à la langue commune et notamment à la langue parlée. Le malaise de l'analyse grammaticale face aux exemples littéraires est manifesté par Gougenheim, qui traite la littérature «comme une sorte de musée des horreurs grammaticales» (p.105) et annonce la «posture paradoxale» de plusieurs grammairiens postérieurs, tels que Grevisse et Le Bidois, qui travaillent sur des exemples littéraires tout en refusant l'idée que ceux-ci garantissent la norme.

5 L' «explication de textes à la française» apparaît, dans le chapitre V, comme la solution trouvée par l'école pour «négocier, au tournant du siècle, le virage épistémologique qu'est la grammaticalisation du concept de littérature» (p.137).

6 Les spécificités de la stylistique française (Albalat, Lanson, C.Bruneau - chap.VI) ressortent de manière évidente dans leur confrontation avec les conceptions allemandes et tout particulièrement avec la notion spitzerienne du «stylème»: l'idée française du style en tant qu'illustration de l'expressivité de la langue s'oppose à l'idée allemande du style comme point d'entrée d'un travail herméneutique portant sur l'auteur.

7 L'héritage du lansonisme et de la tradition scolaire française de l' «explication des textes» pèse encore beaucoup sur l'approche du texte littéraire de Sartre et de Barthes, qui fait l'objet des deux derniers chapitres.

8 Véritable «fil rouge» du «moment grammatical», le style de Flaubert fait encore office de paradigme par rapport auquel les deux écrivains repensent leur propre style.

9 L'évolution sartrienne (chap.VII) mène l'auteur de Qu'est-ce que la littérature? du refus du style flaubertien, dans lequel il reconnaîtrait, d'après G.Philippe, les traits détestés de son propre style, au refus de la notion de style elle-même, au profit d'une conception militante qui ne fait plus de la littérature qu'un acte politique.

10 La lecture barthésienne du style de Flaubert (chap.VIII) montre au contraire comment la génération de Barthes s'inscrit désormais contre l'accent mis sur la grammaire dans la première moitié du siècle. Le tournant épistémologique qui s'opère avec Barthes, tout en marquant la clôture du «moment grammatical» n'est pas exempt lui-même d'une ambiguïté fondamentale, contenant in nuce les enjeux de la réflexion postérieure: une 
«conception sémiotique de la littérature (est littéraire un texte qui donne les signes conventionnels de la littérature)» côtoie toujours «une conception sémantique de la littérature (le texte littéraire correspond à un mode particulier, indirect, de signification») (p.197), qui autorise par un biais différent le retour à une description grammaticale des textes. 